\title{
EL PEDIDO DE 1455 EN EL REINO DE GALICIA
}

\author{
CÉSAR OLIVERA SERRANO \\ Instituto de Estudios Gallegos «Padre Sarmiento»
}

\begin{abstract}
Resumen
Edición de la cuenta del «pedido» de 1455 en Galicia, con una introducción que explica las circunstancias históricas del momento, la información de la toponimia y algunos aspectos económicos relacionados con la recaudación, como la organización de los obispados.
\end{abstract}

\section{Palabras Clave}

Pedido, Cortes de Castilla, recaudación, Galicia, rentas reales

\begin{abstract}
Edition of the account of 1455 "pedido» in the kingdom of Galicia, with a preliminary introduction of the historical environement, some information about places' names and some economic questions related with the taxes collections, like the episcopal economic organization, etc.
\end{abstract}

\section{Key Words}

Pedido, Castilian Cortes, collections, royal incomes 
a edición de fuentes fiscales medievales relativas a Galicia es una actividad necesaria aunque por lo general poco gratificante. No es sencillo sacar conclusiones de conjunto a no ser que se disponga de datos seriados y homogéneos, y en este punto hay demasiadas lagunas. En las páginas que siguen se edita una fuente de especial interés, el pedido de 1455 , único de los conservados de aquel siglo para el conjunto de los reinos de la corona de Castilla, del que se ha sacado la información relativa al Reino de Galicia. El momento histórico es interesante, porque marca el inicio del reinado de Enrique IV (1454-1474), un monarca estrechamente relacionado con las cuestiones más candentes de aquella Galicia convulsa. Hace unos años Francisco Javier Aguado González publicó un avance de este importante documento y resaltó su importancia como fuente para el conocimiento de la toponimia fiscal y de la demografía ${ }^{1}$. Ahora ofrecemos el contenido pormenorizado de los lugares de Galicia sujetos al pago de aquella contribución, aunque conviene advertir que en realidad no sabemos si las cifras se refieren a cantidades ya recaudadas o por recaudar a cargo de la Hacienda real.

Los «pedidos» y «monedas» fueron uno de los principales ingresos extraordinarios votados por las Cortes ${ }^{2}$ durante la baja Edad Media. En el siglo XV, después de la transformación de la alcabala en ingreso ordinario para la corona bajo Enrique III, fueron los únicos «servicios» que otorgaron los procuradores. Galicia tuvo en ese siglo una peculiaridad muy especial, compartida con el Principado de Asturias: fue un territorio exento del pago de monedas y sólo pagó el pedido en muy contadas ocasiones. Las Cortes debatieron mucho sobre la exención fiscal gallega durante los reinados de Juan II y Enrique IV, como ya se ha explicado en otro lugar ${ }^{3}$. Bastará recordar aquí que los procuradores de Cortes siempre consideraron esta situación como algo irregular que debía ser corregido e intentaron una y otra vez -al menos desde 1419- que Galicia volviese a contribuir junto con los restantes reinos, pero el empeño no fue posible, en parte por la resistencia generalizada que hubo en Galicia y también por culpa de la debilidad de las instituciones regias en el territorio gallego. Desde 1425 las ciudades y villas gallegas justifica-

${ }^{1}$ AGUADO GONZÁLEZ, F.J., «Fuentes para la geografía administrativa y distribución de la población en la Corona de Castilla en la segunda mitad del siglo XV: las relaciones de pueblos para el cobro del pedido», Anuario de Estudios Medievales, 16 (1986), pp. 465-480.

${ }^{2}$ Sobre las circunstancias hacendísticas del cobro y gasto de los servicios de Cortes vid. LADERO QUESADA, M.A., La Hacienda real de Castilla en el siglo XV, La Laguna, 1973; del mismo, Fiscalidad y poder real en Castilla (1252-1369), Madrid, 1993.

${ }^{3}$ OLIVERA SERRANO, C., «La ausencia de Galicia en las Cortes del siglo XV», Galicia en la Edad Media, Madrid, 1990, pp. 315-322. 
ron su absentismo fiscal alegando que la causa estaba en la pérdida del voto en Cortes, y hay que reconocer que este argumento tuvo un enorme éxito, pues perduró hasta el siglo XVI. Los sucesivos intentos de «normalización» fiscal bajo Juan II se fueron arriconando en el olvido o la inoperancia hasta que, en 1454, con la subida al trono de Enrique IV, los oficiales reales hicieron un intento serio de resolver la cuestión. De este momento data el documento que editamos. Las Cortes de Córdoba de 1455 acometieron con brío algunas reformas estructurales y entre ellas figuraba la actualización de los servicios de Cortes ¿Utilizaron esos oficiales algún borrador anterior o realizaron uno nuevo? De momento no hay respuesta clara, aunque en el arzobispado de Santiago se cita como modelo de referencia el pedido de 1439.

Hay constancia de que en $1440^{4}$ y $1444^{5}$ se pusieron receptores del pedido en los obispados gallegos junto con las cuatro sacadas de Asturias. A la luz de los escasos resultados disponibles podemos concluir que Galicia siguió sin aportar lo que debía: las Cortes de Madrid-Toledo de 1462 repitieron la vieja y conocida protesta al rey de que Galicia no pagaba. En 1469, a raíz de las Cortes de Ocaña, se hizo una relación del pedido con las 18 monedas que se repartió en todos los partidos del reino ${ }^{6}$, en la que los obispados gallegos figuraban con unas cantidades teóricas, expresadas en maravedíes, algo diferentes a las del año 1455. En el siguiente cuadro se recogen las cantidades que Galicia debería haber pagado en algunos años centrales del siglo XV; a pesar de la parquedad de los datos, se aprecian unas cifras relativamente constantes en cada otorgamiento de pedidos, salvo en 1440, donde sólo se observa la mitad de lo habitual, porque las Cortes de Valladolid sólo otorgaron un pedido sin monedas?

\begin{tabular}{lcrrr}
\hline Obispado & 1440 & \multicolumn{1}{c}{1444} & \multicolumn{1}{c}{1455} & \multicolumn{1}{c}{1469} \\
\hline Santiago y Tuy & 752.825 & 1.532 .985 & 1.503 .340 & 1.803 .504 \\
Orense & 510.575 & 1.020 .504 & 989.950 & 1.225 .260 \\
Lugo & 264.580 & 529.566 & 529.160 & 624.992 \\
Mondoñedo & 262.610 & 525.237 & 525.220 & 630.264 \\
\hline
\end{tabular}

\footnotetext{
${ }^{4}$ AGS, EMR, leg. 2, s.f.

${ }^{5}$ AGS, EMR, leg. 3, s.f.

${ }^{6}$ AGS, EMR, leg. 15, s.f.

${ }^{7}$ OLIVERA SERRANO, C., «Las Cortes de Castilla y el poder real (1431-1444)», En la España Medieval, $\mathrm{n}^{\mathrm{o}} 11$ (1988), p. 258, n. 87.
} 
La cifra global para el conjunto del reino oscila en torno a los 3 millones y medio de maravedíes, destacando por encima del resto el arzobispado de Santiago con el obispado de Tuy, que siempre forman una sola unidad contable. De todas formas hay que tener en cuenta la depreciación del maravedí a lo largo del siglo respecto del oro y la plata ${ }^{8}$, hasta el punto de que en 1470 el descenso equivale a un $70 \%$ de lo que valía en 1429 , de modo que la caída en picado del valor de la moneda de cuenta reducía mucho la carga fiscal de cada contribuyente. Lo que sí destaca con claridad es el peso porcentual de las villas respecto de los señoríos, y en este punto hay que reconocer la razón de ser de las protestas concejiles en contra de la contribución, aspecto éste que reconocen monarcas como Enrique IV en 1462, al afirmar que se necesitaba hacer una nueva «iguala» para lograr el beneplácito de las villas gallegas9.

Los pedidos y monedas se arrendaban, igual que el resto de tributos, y la corona o las mismas Cortes nombraban a los recaudadores mayores. Cuando este procedimiento ordinario no funcionaba correctamente -aquí estaría incluída Galicia- el rey nombraba receptores ${ }^{10}$. Por ejemplo, todos los partidos tributarios de Castilla en 1469 tienen una indicación al margen donde se indica si fueron arrendados o puestos por «receptoría»: los cuatro obispados gallegos tienen en blanco esta anotación, lo cual es señal clara de que no se arrendaron ni recaudaron. La cuenta del pedido que ahora se edita no aporta pistas de ningún tipo sobre el sistema de recaudación previsto. Tan sólo hay una referencia puntual al sistema de repartimiento impuesto en algunos lugares del arzobispado de Santiago, a cargo de sus vecinos.

$\mathrm{Al}$ margen de la cuestión del cobro, la cuenta del pedido sirve para tener una relación global de los lugares que estaban obligados a pagarlo, aunque tampoco podemos deducir el número de habitantes que había en cada uno porque no hay indicación de padrones o cifras de vecinos. Únicamente se podría hacer una estimación económica del valor porcentual de cada lugar dentro de su correspondiente obispado, pero una información de esta naturaleza no puede aportar demasiadas conclusiones demográficas, entre otras razones porque tampoco tenemos noticia de los exentos.

${ }^{8}$ MACKAY, A., Las alteraciones monetarias en la Castilla del siglo XV: la moneda de cuenta y la historia política», En la España Medieval, nº 1 (1980), pp. 237-248; LADERO QUESADA, M.A., «La política monetaria en la Corona de Castilla (1369-1497), En la España Medieval, $\mathrm{n}^{\circ} 11$ (1988), pp. 79-123.

${ }^{9}$ LADERO QUESADA, La Hacienda real de Castilla en el siglo XV, p. 208.

${ }^{10}$ En 1440 fue receptor de los pedidos y monedas de la ciudad de Orense y su obispado Rodrigo Alfonso de Zamora, vecino de Monterrey, cuyo fiador fue Diego López de Astorga; AGS, EMR, leg. 2, s.f.

Cuadernos de Estudios Gallegos, Tomo LI, Fascículo 117, Santiago 2004. (Págs. 363 - 374) 
En definitiva, la mayor utilidad de esta fuente está en relación con la toponimia. Los obispados gallegos constituyen -como en otras rentas reales- la unidad general de los recaudadores, y dentro de cada uno de ellos, aparecen unidades fiscales de tipología muy variada: villas y ciudades con sus alfóces, sacadas, cotos laicos y eclesiásticos, lugares, tierras, valles, feligresías y encomiendas. Salvo en el arzobispado de Santiago, donde aparecen referencias a sus sacadas, el resto de los obispados gallegos carecen de ordenación alguna que haga recordar la existencia de arciprestazgos. En algunos casos se citan los cotos y feligresías de algunos nobles singulares, como Fernán Pérez de Andrade en la sacada de Trastámara, Pedro Álvarez de Sotomayor en la tierra de Sobroso, Fernán Díaz de Ribadeneira en el obispado de Lugo, Vasco Fernández de Párraga y Martín Vázquez de Vaamonde en el mismo obispado, pero no es una regla universal para el conjunto de Galicia. Brillan por su ausencia los estados señoriales de la nobleza titulada. Más frecuentes son las alusiones a los monasterios y sus cotos.

\section{PEDIDO DE GALICIA}

(AGS, EMR, leg. 1, fol. 556-570v)

Arçobispado de Santiago

La sacada de Postomarcos con la çibdad de Santiago con las villas de Noya e Padron e la sacada de entre amos puentes con Pontevedra e Vigo e Redondela e la sacada de Salas con caldas de Reyes e la sacada de deça e con la villa de mellid e con la sacada de santa marta e con finibus terra e la villa de muro e con todas las otras villas e logares e tierras llanas e cotos e feligresias e encomyendas de las dichas sacadas syn malpica e su alfos e traua e sereja que pagan a su parte 757.030 e decontados dellos 2.730 , que monta el pedido de [14]39 es esto que la yglesia de santiago tiene de my por merçed en cada año por juro de heredad por privilegio que son algunos dellos maestros de canteria $\mathrm{e}$ carpenteria e otros ofiçiales de la obra de la dicha yglesia que sean vesinos de la dicha çibdad a rrason de 70 cada, esto finca 754.300 e que los reparta un ome de cada uno de los dichos conçejos qual vos escogieredes. 754.300 .

El conçejo de la villa de la cruña syn los cotos de la dicha villa, 100.930.

Los conçejos de los cotos de la dicha villa de la cruña con las encomiendas que son dentro en los dichos cotos 42.050 e que los reparta un ome de cada uno de los dichos conçejos qual vos escogieredes, 42.050 .

el conçejo de malpica e su alfos, 10.590 .

el conçejo de sereja, 5.710

/I [fol. 556v]

[suma parcial]: 913.580 
el coto de traua, 1.510 .

la villa de betanços e su alfos, 90.840 .

la puente dume, 47.100 .

Ferrol e su alfos, 33.640.

las tierras llanas e cotos e encomiendas que ferrand peres de andrade tiene en la sacada de trastamara contra ortiguera e con todas las otras tierras llanas e encomyendas e ordenes que quales quier personas tienen en la dicha sacada syn sayaya e bregon[roto]nos e syn el coto de gan e syn el coto de trasancos e syn el coto de pedrosa e las caserias del abad e el coto de çeanes e llamas e çerdido e oes e oyes e miño e bramantes que pagan a su parte 164.852 e que los reparte un ome de cada conçejo qual vos escogieredes. 154.852 .

Villalua de montenegro con su alfos 94.190 e que los reparta un ome de cada uno de los dichos conçejos qual vos escogieredes. 94.190.

el coto de çeans, 13.450 . [suma parcial]: 432.140.

llamas e çerdido, 4.710 .

oes e oyes, 5.890

miño e bramantes, 5.210 .

la feligresia de belsar, 1.340 .

la feligresia de berreros, 830 .

santas vayas de donas, 2.850

manifre, 3.190.

gondomar e fronçelos, 2.850

Villaça, 1.500 .

[suma parcial]: 40.330 .

cubia e negroa e anido e temellosa con parada, 4.370.

felgueras, 2.680 .

choyn, 1.140.

la guarda con su alfos, 12.780 .

los cotos de oya, 9.220 .

el coto de temyño con llamamala e teba e sobrada, 12.780 .

barrantes, 3.530 .

viñales e persegueros, 3.560 .

[suma parcial]: 51.560.

tierra de enteça syn bodino, 9.920 .

arcas, 2.760

el coto de bodino, 3.530 .

amorin, 1.850 .

Val de loriana (...) 11.100 .

las ferrerias e tierra de soberoso con los cotos del abad de melon e del obispo syn las feligresias que tiene en la dicha tierra Pero aluares de sotomayor, 36.160 .

[suma parcial]: 65.320 .

Monta el pedido deste arçobispado [en blanco, debería poner 1.503.340]

II [fol. 558v]

Cuadernos de Estudios Gallegos, Tomo LI, Fascículo 117, Santiago 2004. (Págs. 363 - 374) 
Obispado de Orense

el conçejo de la çibdad de Orense con los cotos del obispo e con el coto de çebollido, 126.170.

el conçejo de castro caldelas con su tierra e con el coto de san eloy e sant payo e caruajal e castro de boadas e sant vicente e (...) e Regada, que son de santa maria de carrasedo, con tierra de mansaneda syn la encomienda de san viçente e con el coto de cobin e la yglesia e encomienda de [roto]rratan e la encomienda [roto] e la encomienda de pue[roto] de Val de orres e su tierra e [roto] quiroga de cabo del castillo [roto]nas e el coto de santa crus [roto] tierra de calas syn la encomienda [roto] sobrada, 126.170 .

la villa de millmanda, 14.010 .

tierra de saande e su alfos, [roto]

el coto de furedos, [roto]

el conçejo de villa nueva de los ynfantes, 9.010 .

la villa de allaris con su alfos, 21.020.

el judgado de çelanoua, 27.910.

$/ /$ fol. 559v]

[suma parcial]: 346.620 .

arnoya e la beseria, 35.660 .

la encomienda de Ramiraes e asevedo, 21.240.

tierra de Vade, 18.440.

congosto e ordenes e paraçelas, 2.860 .

prado e viadar e sorga e sant gullado con el coto de monesterio de vega, 4.380.

la ribera de parente, 4.370 .

el coto de santa locadia, 5.540 .

el coto de san çebrian, 4.870 .

$/ /$ [fol. 560]

[suma parcial]: 97.360

el coto de castrillo, 2.530 .

montes de rriba de miño, 36.170 .

mesquita e gargançones, 4.380 .

el coto de santa e villa de suso, 1.850 .

el coto de pinedo, 1.490 .

tierra de lobera e entre miño (sic) con gra e fora e montaos, 23.100.

tierra de tudea, 5.670.

el coto de torneros, 530 .

$/ /$ [fol. 560v]

[suma parcial]: 75.720.

tierra de arneda con la puente de anbia, 12.780 .

tierra de sandino con la casa de sandin, 21.530.

molgas e sant viçente e pynero, 4.880 .

los cotos de sandianes e parada, 9. 320 .

coron e soto mayor e oranes e entramos Rios, 4.880 .

el coto de san esteuan de rriba de sil, 12.770 . 
el coto de santa marina de aguas santas, 7.230.

los cotos de yunquera de anbia, 5.710.

// [fol. 561]

[suma parcial]: 79.190.

monte Rey e su alfos, 46.260 .

lugares e cotos e feligresias de casa de lima e con el coto de rio caldo e syn la dicha villa de monte Rey e su alfos, 56.930 .

la villa de Riba de auia, 33.640.

tierra de orsellon con tormeda e parada e la viaria, 49.630.

castro de couadoso con su alfos, 5.710 .

los cotos de anllo, 10.760 .

los cotos de san eloyo, 10.760 .

veron e veran, 2.890 .

// [fol. 561v]

[suma parcial]: 216.580.

ortega, 3.850 .

santo tomas e seranos, 6.570

caruallido e moymando, 6.570 .

avellaneda das penas, 1.500 .

guila folguera, 4.550 .

veynde e vayte, 4.380 .

tierra dos chaos de castela, 18.000.

los cotos de melon, 10.760 .

// [fol. 562]

[suma parcial]: 56.180.

domero e pelanas, 19.170 .

tierra de avion, 24.730.

el bollo de senda, 9. 920.

Çella e Villarino, 3.520.

el conçejo de [roto]les syn montes e Riba e san Juan de poles, 8.580.

el conçejo de melos e Ribera con sant Juan de poles, 11.420.

el coto de agosto, 3.540.

el conçejo de leon, 9.920 .

$/ /$ fol. $562 \mathrm{v}]$

[suma parcial]: 90.810.

rodero e cañedo con santiago de lomas, 5.710.

el coto de doçon, 9.420 .

tierra de aguiar, 36.330 .

el coto de otalvos e praguero, 460 .

el conçejo de areys, 220.

el conçejo de amorin, 220.

el conçejo de tierra de cardeas (sic) con bodino, 1.560 .

el conçejo de val de oma con las benfetadas, 1.380 .

[suma parcial]: 25.400

Cuadernos de Estudios Gallegos, Tomo LI, Fascículo 117, Santiago 2004. (Págs. 363 - 374) 


\section{$/ /$ [fol. 563]}

el conçejo del coto de lodeño, 220.

los conçejos de las feligresias de tierra de soberoso con los cotos del abad de melon e del obispo syn las feligresias que tiene en la dicha tierra Pero alvares de soto mayor, 2.860. Monta el pedido deste obispado [en blanco; debería poner 989.950]

// [fol. 564]

obispado de lugo

la çibdad de lugo con sus cotos, 99.240 .

castro verde e su alfos, 5.710 .

oter de Rey e su alfos, 5.710 .

la puebla de adan e su alfos, 5.710 .

Castro de Rey e su alfos, 4.880 .

el conçejo de buron e su alfos, 14.290 .

el conçejo de la puebla de navia e su alfos, 2.180.

loases e su tierra, 1.510 .

[suma parcial]: 139.230 .

$/ /$ [fol. 564v]

el coto de goya, 9.440 .

saavedra e Riba de miño e german e los cotos de ferrand dias de rribadeneyra, 2.440.

don alvaar, 750 .

Villa mon, 1.120 .

los cotos de Vasco ferrandes de parraga que son santillana de duesa e santo tome de boueda, 2.180 .

narla, 2.520 .

pedra fita, 530 .

onbreyro, 1.540 .

[suma parcial]: 30.520 .

quintela e castro dos frayres, 5.210.

Roanes, 3.160 .

Ribadenllo, 5.540.

Ynfantes, 330.

Villadonga, 3.020.

las Riberas do bea, 1.000 .

calos, 2.530 .

sant cloyo, 840 .

$/ /$ fol. 565v]

[suma parcial]: 21.630.

mexia, 12.440 .

el coto de creçiente, 5.890 .

el coto do bea, 5.890.

el coto de pianços con Remyn, 670. 
el coto de silua e andea, 670 .

el coto de sant çebrian, 6.040 .

el coto de peña, 1.000 .

avellora e martin cabellado e la fontanera, 8.070.

[suma parcial]: 40.670 .

// [fol. 566]

Formes e Bacurello, 1.510

Riomol, 670

Neyra de Rey e su tierra e asevedo e faro e castellanos con los cotos del abad de Peñamayor, 3.020

Fonteyra, 2.020

Sant andres, 1.000

Sant cristoual e sant Julian, 1.210

Partido, 1.000

Sobrada e sant llorente de Aguiar, 2.380

[suma parcial]: 12.800

// [Fol. 566v]

sant martin de perelpos, 670

los cotos de martin vasques de Vaamonde, que son Santiago e Vaamonde e sant Martin de

Perenços e sant Pedro de parraga e corral e santa maria de Castro e osas (ilegible) e

Feynta, 2.870

Sarria e su alfos, 12.780

Triacastela y su alfos, 3.020

La puebla de sant julian e su alfos, 1.850

Tierra de Samos, 10.930

Porto marin del cabo de sarria con el coto de layo, 5.710

Porto marin del cabo de la orden, 5.210

[suma parcial]: 44.040

// [fol. 577]

tierra de curiel, 5.560

paramo con godia, 4.380

el coto de andio, 1.510

tierra de Valboa, 3.690

paradalle, 670

neyra e ynsua, 3.690

pinera, 1.340

la villa de monforte e su alfos, 15.300

[suma parcial]: 36.130

$/ /[$ fol. $567 \mathrm{v}]$

la puebla de burullon e su alfos e cotos segund suelen andar, 11.240

sandianes e sardinera, 8.580

novielas, 670

Cuadernos de Estudios Gallegos, Tomo LI, Fascículo 117, Santiago 2004. (Págs. 363 - 374) 
panton, 7.060

Versal e diamonde, 2.520

Atan, 2.520

Villar de tello, 2.520

Poonbeyro, 2.520

[suma parcial]: 37.630

//[fol. 568]

Valdeherrero, 6.380

Doade, 3.700

Amande, 3.700

Lobios, 670

El coto de Villa Nueva, 670

Yros, 670

leer, 2.520

gondin e canedo, 1.340

$/ /[$ fol. $568 \mathrm{v}]$

[suma parcial]: 19.650

freytuy, 670

la Somoça de Lemos, 5.210

boueda, 1.510

Sedra e layosa, 1.510

Los castellones e turis, 1.850

Yunça, 2.190

Monte Roso, 24.380

Chantada e su alfos, 28.590

[suma parcial]: 65.910

tonos e villa Ramuyn desde unital fasta el agua de la barra, 14.300

Canba e Rodero, 10.600

Tierra de Rebolledo, 10.600

Tierra del ospital, 2.360

El coto de Sobrado, 10.290

Tierra de Ulloa e la Reposteria, 32.800

[suma parcial]: 80.950

Suma deste obispado, 529.160

// [fol. 570]

Obispado de Mondoñedo

La villa de bivero con sus valles e terminos, 127.840

Villanueva e lorençana con su abadengo e con el val de lorençana, 23.750

La villa de Ribadeo, 42.040

Los conçejos e moradores e pobladores de la tierra llana de mondoñedo con la çibdad de Villa mayor e con Vares e mogor e rriberas de sor e galdo e landrove e grallal, 199.690 
Santa marta e su alfos, 58.030

Las puentes de garçia Rodrigues, 21.860

Tierra de trasancos, 7.060

El coto de pertoso, 5.540

[suma parcial]: 485.810

los casares del abad, 2.580

Çedera e su alfos, 26.410

Neda e su alfos, 10.420

[suma parcial]: 39.410

Suma deste obispado, 525.220. 